\title{
Formononetin inhibits tumor growth by suppression of EGFR-Akt-Mcl-1 axis in non- small cell lung cancer
}

Xinyou Yu ${ }^{1,2+}$, Feng Gao ${ }^{1,3+}$, Wei $\mathrm{Li}^{1,4^{*}}, \mathrm{Li}_{\text {Zhou}}^{5}$, Wenbin Liu ${ }^{6}$ and Ming Li ${ }^{7,8}$

\begin{abstract}
Background: Epidermal growth factor receptor (EGFR) activating mutations play crucial roles in the tumorigenesis of human non-small cell lung cancer (NSCLC). The mechanism regarding how EGFR signaling regulates myeloid cell leukemia sequence 1 (Mcl-1) protein stability and ubiquitination remains undefined.

Methods: MTS assay was used for natural product library screening. The effect of formononetin (Formo) on NSCLC cells was determined by MTS assay and soft agar assay. Molecular modeling was performed to analyze the potential different binding modes between Formo and EGFR WT or mutants. Mcl-1 protein level and the inhibitory effect of Formo on EGFR signaling were examined by immunoblot, in vitro kinase assay, in vitro pulldown and ATP competition assays, coimmunoprecipitation assay, ubiquitination analysis, in vivo xenograft model, and immunohistochemical staining.

Results: Formo was identified as an EGFR inhibitor by a 98 commercially available natural product screening. Formo suppresses WT and mutant EGFR kinases activity in vitro, ex vivo, and in vivo. Molecular modeling indicates that Formo docks into the ATP-binding pocket of both WT and mutant EGFR. Formo inhibits EGFR-Akt signaling, which in turn activates GSK3 $\beta$ and promotes Mcl-1 phosphorylation in NSCLC cells. Treatment with Formo enhances the interaction between $\mathrm{MCl}-1$ and $\mathrm{SCF}^{\mathrm{Fb} w 7}$, which eventually promotes $\mathrm{MCl}-1$ ubiquitination and degradation. Depletion of either GSK3 $\beta$ or SCF ${ }^{\mathrm{Fb} w 7}$ compromised Formo-induced Mcl-1 downregulation. Finally, Formo inhibits the in vivo tumor growth in a xenograft mouse model.

Conclusion: This study highlights the importance of promoting ubiquitination-dependent Mcl-1 turnover might be an alternative strategy to enhance the anti-tumor efficacy of EGFR-TKI.
\end{abstract}

Keywords: Non-small cell lung cancer, Formononetin, Epidermal growth factor receptor, Mcl-1, Ubiquitination

\section{Background}

Non-small cell lung cancer (NSCLC) is one of the most lethal cancers. Epidermal growth factor receptor (EGFR) activating mutations are considered as a driving force for tumorigenesis of some NSCLC. Over $90 \%$ of EGFR

\footnotetext{
*Correspondence: weililx@csu.edu.cn

${ }^{\dagger}$ Xinyou Yu and Feng Gao contributed equally to this work.

'Cell Transplantation and Gene Therapy Institute, The Third Xiangya Hospital, Central South University, Changsha, Hunan 410013, P.R. China

${ }^{4}$ Department of Radiology, The Third Xiangya Hospital of Central South University, Changsha, Hunan 410013, P.R. China

Full list of author information is available at the end of the article
}

activating mutations which occur in both Asian and Western NSCLC patient present as an exon 19 deletion $(60 \%)$ or exon 21 point mutation (30\%) [1-3]. Targeting therapy with the tyrosine kinase inhibitors (TKIs), such as gefitinib and erlotinib, has become the first-line treatment for these patients with EGFR activating mutations. However, most patients who initially respond to TKIs eventually develop acquired resistance. Beyond c-Met amplification, previous studies reveal that over $60 \%$ of acquired resistant cases associated with the emergence of a secondary mutation of EGFR, T790M. The

C C The Author(s). 2020 Open Access This article is licensed under a Creative Commons Attribution 4.0 International License, which permits use, sharing, adaptation, distribution and reproduction in any medium or format, as long as you give appropriate credit to the original author(s) and the source, provide a link to the Creative Commons licence, and indicate if changes were made. The images or other third party material in this article are included in the article's Creative Commons licence, unless indicated otherwise in a credit line to the material. If material is not included in the article's Creative Commons licence and your intended use is not permitted by statutory regulation or exceeds the permitted use, you will need to obtain permission directly from the copyright holder. To view a copy of this licence, visit http://creativecommons.org/licenses/by/4.0/ The Creative Commons Public Domain Dedication waiver (http://creativecommons.org/publicdomain/zero/1.0/) applies to the data made available in this article, unless otherwise stated in a credit line to the data. 
threonine to methionine mutation, which occurs in the EGFR tyrosine kinase domain, promotes ATP binding affinity and attenuates the interaction between EGFR tyrosine kinase domain and the first-generation reversible EGFR-TKIs $[4,5]$. Osimertinib represents the thirdgeneration EGFR-TKIs, which irreversibly inhibit EGFR activating mutations, overcomes EGFR T790M secondary mutation conferred acquired resistance to first- and second-generation TKIs. Although osimertinib significantly improved the progression-free survival (PFS) of NSCLC patients with EGFR T790M mutation, the development of acquired resistance to the third-generation EGFR-TKIs has already been described and increased in the clinic [6-8]. However, the precise mechanisms mediating resistance to osimertinib remain largely unknown, and the strategies to overcome osimertinib resistance are still limited.

Myeloid cell leukemia sequence 1 (Mcl-1) is a member of the pro-survival Bcl-2 family that negatively regulates the mitochondrial apoptotic pathway. Overexpression or amplification of Mcl-1 is frequently observed in human cancers and associated with poor prognosis. Inhibition of Mcl-1 sensitizes chemo/radiotherapy induced apoptosis in multiple cancer models [9-11]. Recent studies showed that Mcl-1 is upregulated by EGFR signaling. For example, EGF stimulation enhances Mcl-1 transcription in a transcription factor Elk-1 dependent manner [12]. In EGFR mutant NSCLC cells, hyperactivation of mTORC1 increased Mcl-1 mRNA level and conferred EGFR TKI resistance [13]. The mechanisms regarding EGFR activation and Mcl-1 transcription were well studied previously. However, the mechanisms underlying how EGFR signaling regulates Mcl-1 protein stability, as well as ubiquitination, remains elusive.

Previous studies have demonstrated that the natural compound, formononetin $\left(\mathrm{C}_{16} \mathrm{H}_{12} \mathrm{O}_{4}\right)$, exhibits significant anti-tumor potentials against human cancers [14, 15]. The evidence from in vitro and in vivo studies reveal that Formo acts as a novel anti-tumorigenic agent to induce cell cycle arrest, apoptosis, anti-angiogenesis, and metastasis in a panel of solid tumors, including lung cancer [16], colorectal cancer [17], breast cancer [18], and gastric cancer [19]. The mechanism studies indicate that deactivation of protein kinases and signal transduction, or dysfunction of oncogenetic-related transcription factors, are involved in Formo-induced anti-tumor activities $[14,15]$. However, the inhibitory efficacy of Formo on EGFR signaling, and the anti-tumor effect of Formo on both osimertinib sensitive and resistant NSCLC cells, is not clear.

In the present study, by the screening of a natural products library, we identified Formo, a flavonoid derivative [18], as a potential anti-tumor agent for use in NSCLC therapy. We investigated the therapeutic effect using NSCLC cell lines and determined the underlying mechanism of action.

\section{Materials and methods \\ Reagents and antibodies}

The screened compound library (L1400) was a product of Selleck Chemicals (Houston, TX). The inhibitors, including Necrostatin-1, GSK'872, z-VAD-fmk, MG132, SB216763, PD98059, and LY294002, were purchased from Selleck Chemicals. Cell culture medium, Fetal Bovine Serum (FBS), and supplements were purchased from Invitrogen (Grand Island, NY). Primary antibodies against EGFR (\#4267, 1:1000), ERK1/2 (\#9102, 1:1000), Akt (\#4691, 1:1000), p-EGFR-Tyr1068 (\#3777, 1:1000), p-ERK1/2-Thr202/Tyr204 (\#4370, 1:1000), p-Akt-Ser473 (\#4060, 1:1000), PARP (\#9532, 1:1000), cleaved-caspase 3 (\#9664, 1:1000), Bax (\#14796, 1:1000), VDAC1 (\#4661, 1:2000), cytochrome C (\#11940, 1:1000), Mcl-1 (\#39224, 1:1000), ubiquitin (\#3936, 1:1000), ubiquitin (\#43124, 1: 1000), $\alpha$-Tubulin (\#2125, 1:5000), GSK3 $\beta$ (\#12456, 1 : $1000)$, and $\beta$-actin (\#3700, 1:10000) were purchased from Cell Signaling Technology, Inc. (Danvers, MA). Flag-tag (F3165, 1:5000) antibody was obtained from Sigma Aldrich (St. Louis, MO). Antibodies against FBW7 (ab109617, 1:1000) and FBW7 (ab187815, 1:1000) were obtained from Abcam (Cambridge, UK). Antibodies for immunohistochemistry staining (IHC), including anti-ki67 (ab15580, 1:300) and anti-p-Akt (ab81283, 1:100) were obtained from Abcam. Anti-p-EGFR (\#3777, 1:200), and anti-Mcl-1 (\#39224, 1:100) were purchased from Cell Signaling Technology, Inc.

\section{Cell culture}

Human NSCLC cells, including HCC827 (EGFR Del E746-A750), H3255 (EGFR L858R), H1975 (EGFR L858R/T790M), A549 (EGFR WT), and H1299 (EGFR WT) were purchased from American Type Culture Collection (ATCC, Manassas, VA). Cells were maintained at $37^{\circ} \mathrm{C}$ in a humidified incubator with $5 \% \mathrm{CO}_{2}$ according to ATCC protocols. The osimertinib acquired resistance cell line HCC827 OR was established in our laboratory by exposing $\mathrm{HCC} 827$ cells to gradually increasing concentration of osimertinib for approximately 5 months (starting at $5 \mathrm{nM}$ and ending with $500 \mathrm{nM}$ ). All NSCLC cells were subjected to mycoplasma analysis and cytogenetically tested before being frozen. The immortalized epithelial cells NL20 and HBE were purchased from ATCC and cultured following the standard protocols. $\mathrm{Ba} / \mathrm{F} 3$ cell was obtained from Cell Engineering Division/ RIKEN BioResource Center (Tsukuba, Ibaraki, Japan) and maintained in RPMI $1640+10 \%$ FBS + 10\% WEHI-3 cell conditioned medium according to instructions provided. Lipofectamine 2000 (Thermo Fisher Scientific) 
transfection reagent was used for plasmid transfection following the manufacturer's instructions.

\section{Immunoblotting}

Immunoblotting (IB) was performed as described previously [20]. Whole-cell lysate was prepared with RIPA buffer (10 mM Tris-Cl (pH 8.0), $1 \mathrm{mM}$ EDTA, $0.5 \mathrm{mM}$ EGTA, 1\% Triton X-100, 0.1\% sodium deoxycholate, $0.1 \%$ SDS. $140 \mathrm{mM} \mathrm{NaCl}$ ) supplied with phosphatase and protease inhibitors, BCA kit (\#23225, Thermo Fisher Scientific) was used for protein concentration. The whole-cell lysate was boiled with loading buffer and subjected to SDSPAGE gel electrophoresis and antibody hybridization. The target proteins were visualized by chemiluminescence (Amersham Biosciences, Piscataway, NJ).

\section{Isolation of subcellular fractions}

The Mitochondria Isolation Kit (\#89874, Thermo Fisher Scientific) was used for subcellular fractions preparation according to the standard instructions.

\section{MTS assay}

NSCLC cells were seeded $\left(2.5 \times 10^{3} /\right.$ well $\left./ 100 \mu \mathrm{L}\right)$ in 96well plates and treated with Formo or osimertinib, as indicated. Cell viability was examined using MTS assay (Promega, Madison, WI) following the instructions provided.

\section{Anchorage-independent cell growth}

The anchorage-independent cell growth assay was performed as described previously [21]. Briefly, the Eagle's basal medium containing $0.6 \%$ agar, $10 \%$ FBS, and different concentration of Formo or osimertinib was loading to a six-well plate as an agar base. Cells were then counted at the concentration of 8000 cells $/ \mathrm{ml}$ with the Eagle's basal medium containing 10\% FBS, 0.3\% agar, Formo, or osimertinib, followed by overlaid into the sixwell plate containing a $0.6 \%$ agar base. The cultures were maintained in a $37^{\circ} \mathrm{C}, 5 \% \mathrm{CO}_{2}$ incubator for 2 weeks and counted using a microscope.

\section{Stable lines generation}

EGFR cDNA clones, including WT EGFR, L858R EGFR, L858R/T790M EGFR, and Del E746-A750 EGFR, were subcloned into the lentivirus vector by SgfI and MluI. The Lentiviral Packaging Kit (TR30037, Origene) was used for virus package in $293 \mathrm{~T}$ cells. The Ba/F3 cells were infected with lentivirus together with $8 \mu \mathrm{g} / \mathrm{mL}$ polybrene for $24 \mathrm{~h}$. Two days later, $2 \mu \mathrm{g} / \mathrm{mL}$ puromycin was added to the cell culture medium and maintained for another 7 days for stable cell selection.

\section{In vitro EGFR kinase assay}

The recombinant active WT EGFR, L858R EGFR, L858R/ T790M EGFR, and Del E746-A750 EGFR were purchased from Millipore. The in vitro EGFR kinase assay was performed as described previously [22]. Briefly, active EGFR (100 ng) was mixed with various doses of Formo or 100 $\mathrm{nM}$ osimertinib. The reaction was incubated with $500 \mu \mathrm{M}$ angiotensin II for $5 \mathrm{~min}$ at room temperature, followed by incubation with $10 \mu \mathrm{L}$ of ATP mixture $(25 \mathrm{mM} \mathrm{MgAc}$ and $0.25 \mu \mathrm{M}$ ATP containing $10 \mu \mathrm{Ci}[\gamma-32 \mathrm{P}] \mathrm{ATP})$ for $15 \mathrm{~min}$ at $30^{\circ} \mathrm{C}$ and then $25 \mu \mathrm{L}$ of the reaction mixture was transferred onto P81 papers. The papers were washed with $0.75 \%$ phosphoric acid twice and then with acetone once. The radioactive incorporation was determined using a scintillation counter.

\section{In vitro pulldown and ATP competition assays}

The in vitro pulldown and ATP competition assays were performed as described previously [23]. FormoSepharose 4B beads were prepared following the protocol provided by GE Healthcare Biosciences. NSCLC cell lysate $(500 \mu \mathrm{g})$ or an active kinase with different concentrations of ATP was incubated with Formo-Sepharose 4B beads or Sepharose 4B beads only in reaction buffer (50 mM Tris- $\mathrm{HCl}$ (pH 7.5), $150 \mathrm{mM} \mathrm{NaCl}, 5 \mathrm{mM}$ EDTA, $1 \mathrm{mM}$ DTT, $0.01 \%$ Nonidet P-40, $0.02 \mathrm{mM}$ phenylmethylsulfonyl fluoride, $1 \times$ protease inhibitor mixture and $2 \mu \mathrm{g} / \mathrm{mL}$ bovine serum albumin) at $4{ }^{\circ} \mathrm{C}$ with gentle rocking overnight, followed by washing with washing buffer (50 mM Tris- $\mathrm{HCl}$ (pH 7.5), $150 \mathrm{mM} \mathrm{NaCl}, 5 \mathrm{mM}$ EDTA, $1 \mathrm{mM}$ DTT, and $0.01 \%$ Nonidet P-40, and 0.02 $\mathrm{mM}$ phenylmethylsulfonyl fluoride) 5 times. Protein binding was analyzed by IB.

\section{Molecular Modeling Homology modeling}

The three-dimensional structure of EGFR with exon 19 deletion mutant (residues E746-A750) was modeled based on the wild type (WT) crystal structure of EGFR using Modeller [24]. Through extensive analysis of the deposited structures in Protein Data Bank (PDB) [25], the crystal structure of EGFR (PDB: 4JR3) was used as the template for homology modeling. Ten models were generated and evaluated with the Discrete Optimized Protein Energy (DOPE) score implemented in Modeller. Finally, the best model was adapted for the subsequent docking studies.

\section{Molecular docking}

The structures of WT EGFR (PDB: 4JR3), L858R EGFR (PDB: 2ITV), L858R/T790M EGFR (PDB: 3W2P), and exon 19 deletion EGFR were prepared, including filling in missing side chains, adding hydrogens and minimizing heavy atoms with default parameters using Protein 
Preparation Wizard in Schrödinger Suite 2013. Then the structure file of the ligand, Formo, was well pretreated in LigPrep, and docking was performed based on the standard precision mode of Glide with default settings. Docking poses for each receptor-ligand complex were then analyzed for binding modes, and final figures were generated using PyMOL. Hydrogen bond lengths were defined as the distance between the donor and acceptor atom centers.

\section{Refine and MM-GBSA}

Prime was employed to further refine the binding pose and calculate binding free energy (i.e. $\Delta G$ ) by the MMGBSA method using the Prime MM-GBSA module in Schrödinger Suite 2013. Residues with distances from the ligand within $12.0 \AA$ were set as flexible. Other settings were kept in default.

\section{Ubiquitination assay}

The ubiquitination assay was performed as described previously [26]. Cells were lysed with modified RIPA buffer containing 1\% SDS (20 mM NAP, pH 7.4, 150 $\mathrm{mM} \mathrm{NaCl}, 1 \%$ Triton, and 0.5\% Sodium-deoxycholate), protease inhibitors, and $10 \mathrm{mM} \mathrm{N}$-Ethylmaleimide (NEM). The lysates were sonicated for $30 \mathrm{~s}$ and boiled at $95^{\circ} \mathrm{C}$ for $15 \mathrm{~min}$, then diluted with $0.1 \%$ SDS containing RIPA buffer and centrifuged at $16000 \times \mathrm{g}$ for $15 \mathrm{~min}$. The supernatant was transferred to a new tube and incubated with Mcl-1 antibody plus protein A-Sepharose beads overnight at $4{ }^{\circ} \mathrm{C}$. Beads were washed and subjected to IB analysis.

\section{In vivo tumor growth}

All mice experiments were performed according to strict guidelines established by the Medical Research Animal Ethics Committee, Central South University, China. NSCLC cells, including HCC827 cells $\left(2 \times 10^{6}\right)$, H1975 $\left(1 \times 10^{6}\right)$, A549 $\left(2 \times 10^{6}\right)$ and H3255 $\left(2 \times 10^{6}\right)$ were counted and suspended in $100 \mu \mathrm{L}$ RPMI-1640 medium and inoculated s.c. into the right flank of 6-week-old female athymic nude mice (6 mice per group). Formo (10 $\mathrm{mg} / \mathrm{kg}$ ) or vehicle control was administrated daily by i.p. Injection when the tumor volume reached $100 \mathrm{~mm}^{3}$, whereas osimertinib $(2 \mathrm{mg} / \mathrm{kg})$ was initiated and repeated daily by oral gavage. Mouse body weight was recorded, and tumor volume was determined by caliper. Tumor volume was calculated following the formula of $\mathrm{A} \times \mathrm{B} 2 \times 0.5$, wherein $\mathrm{A}$ is the longest diameter of the tumor, B is the shortest diameter, and B2 is B squared.

\section{Immunohistochemical (IHC) staining}

IHC staining was performed as described previously [27]. Briefly, tissue sections from xenograft tumor tissues were deparaffinized and rehydrated. The slide was unmasked by submersion into boiling sodium citrate buffer $(10 \mathrm{mM}, \mathrm{pH}$ 6.0) for $10 \mathrm{~min}$, followed by treating with $3 \% \mathrm{H}_{2} \mathrm{O}_{2}$ for $10 \mathrm{~min}$ at room temperature. The tissue slide was blocked with $50 \%$ goat serum albumin in a humidified chamber at room temperature for $1 \mathrm{~h}$, then incubated with the primary antibody at $4{ }^{\circ} \mathrm{C}$ overnight. After hybridized with the second antibody for $45 \mathrm{~min}$ at room temperature, the slide was incubated with $\mathrm{DAB}$ substrate for target protein visualization. Hematoxylin was used for counterstaining.

\section{Blood analysis}

Mouse whole blood $(200 \mu \mathrm{L})$ was collected in EDTAcoated tubes via cardiac puncture. The count for red blood cells (RBC) and white blood cells (WBC), hemoglobin $(\mathrm{Hb})$, alanine aminotransferase (ALT), aspartate aminotransferase (AST), and blood urea nitrogen (BUN) were analyzed at the Laboratory of the Third Xiangya Hospital (Changsha, China).

\section{Statistical analysis}

Statistical analyses were performed using SPSS (version 16.0 for Windows, SPSS Inc., Chicago, IL, USA) and GraphPad Prism 5 (GraphPad 5.0, San Diego, CA, USA). The quantitative data were expressed as means \pm SD. Significant differences were determined by the Student t-test or ANOVA. A probability value of less than 0.05 was used as the criterion for statistical significance.

\section{Results}

Formononetin (Formo) inhibits both osimertinib sensitive and resistant NSCLC cells

To discover natural products that can inhibit NSCLC cells, we screened a library of 98 commercially available compounds (Supplementary Table 1) using MTS assay. Our data indicated that only Formo decreased the cell viability of $\mathrm{HCC} 827$ cells over $20 \%$ at the concentration of $3 \mu \mathrm{M}$ (Fig. 1a and b). To confirm the anti-tumor effect, we examined the inhibitory effect of Formo on osimertinib sensitive cells, HCC827 (EGFR Del E746A750), H3255 (EGFR L858R), and H1975 (EGFR L858R/ T790M), and osimertinib resistant cells A549 (EGFR WT), H1299 (EGFR WT), and HCC827 OR (osimertinib acquired resistant). The MTS result showed that osimertinib only decreased the cell viability of osimertinib sensitive NSCLC cells, but not the resistant NSCLC cells or the immortalized lung epithelial cells HBE and NL20 (Fig. 1c). In contrast, Formo exhibited a significant inhibitory effect on both osimertinib sensitive and resistant cells (Fig. 1d). Moreover, the MTS result showed that when concentration less than $10 \mu \mathrm{M}$, Formo did not decrease the cell viability of HBE and NL20 cells (Fig. 1d), suggesting that Formo is well tolerated in normal epithelial cells. We further examined colony formation of 


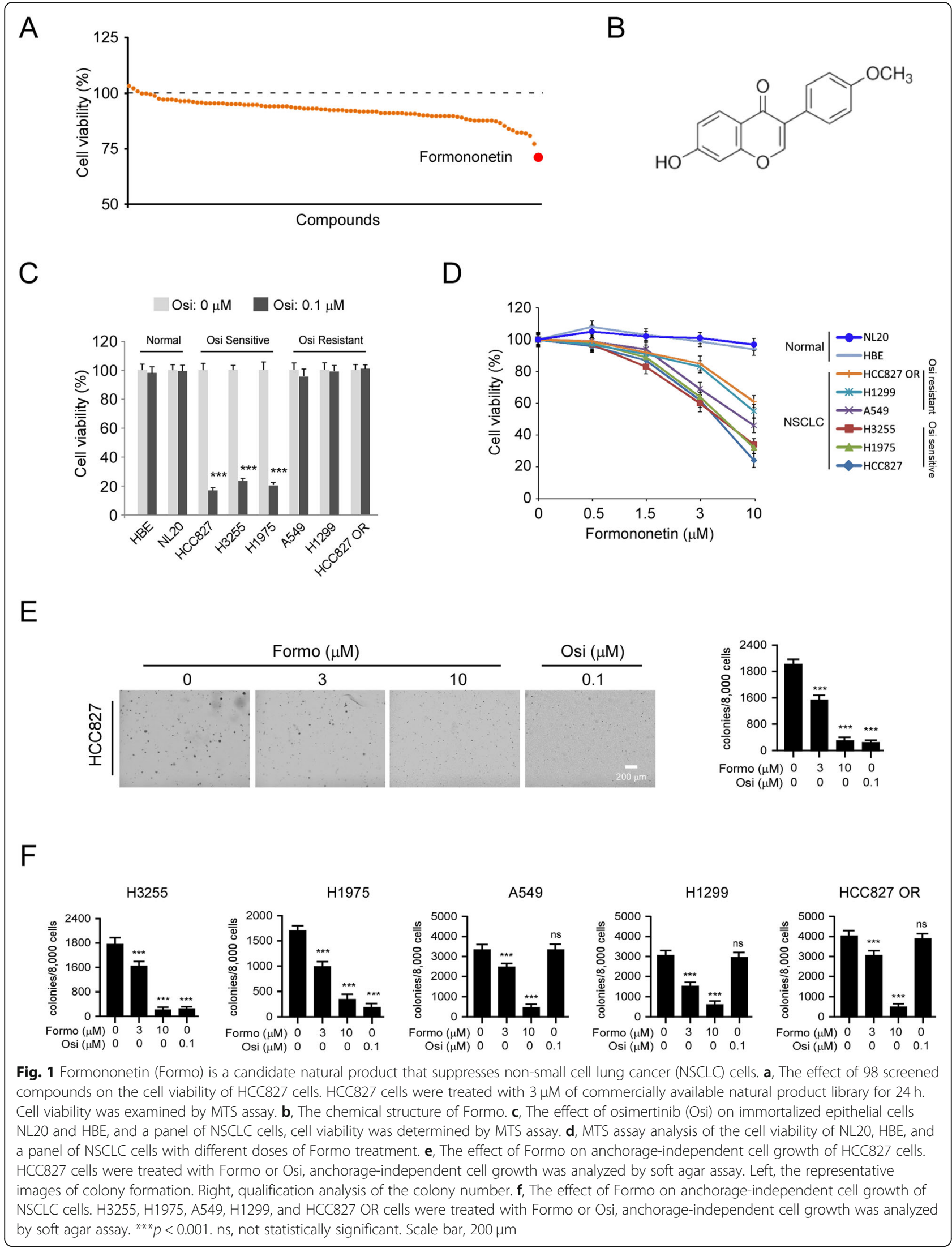


NSCLC cells with Formo or osimertinib treatment using soft agar assay. The results showed that osimertinib inhibited the anchorage-independent cell growth of osimertinib sensitive cells, but not the resistant cells as expected. Consistent with the MTS data, Formo decreased the colony formation of HCC827, H3255, H1975, A549, H1299, and HCC827 OR cells at various concentrations (Fig. 1E AND F, Supplementary Figure 1A-E). Our results suggest that Formo inhibits cell growth of both osimertinib sensitive and resistant NSCLC cells.

\section{Formo suppresses EGFR signaling ex vivo and in vitro}

To determine the anti-tumor mechanisms of Formo, we first examined the effect of Formo on EGFR signaling. Using the in vitro pulldown assay, we analyzed the interaction between Formo and EGFR WT/activating mutants (Del E746-A750, L858R, L858R/T790M) ex vivo. By incubation with the whole-cell lysates from HCC827, H1975, H3255, and A549 (Fig. 2a), we demonstrated that EGFRs were pulled down by Formo-conjugated Sepharose 4B beads but not by Sepharose 4B beads alone, indicating that both WT EGFR and mutant EGFRs can bind with Formo. The in vitro kinase assay showed that both Formo and osimertinib significantly decreased the kinase activity of activating mutants, Del E746-A750, L858R, and L858R/T790M. Furthermore, Formo, but not osimertinib, impaired the kinase activity of EGFR WT (Fig. 2b).

We next performed molecular modeling to analyze the potential different binding modes between Formo and EGFRs. Formo was docked into the ATP-binding pocket of various forms of EGFR, including the wild type, L858R single mutation, L858R/T790M double mutations, and exon 19 deletion. Then the binding poses were refined and calculated binding free energy $(\Delta G)$. The predicted trend of $\Delta G$ for these types of EGFR was in accordance with the experimental results. Their values were $-43.6,-48.8,-45.1$ and $-50.9 \mathrm{kcal} / \mathrm{mol}$, respectively. As shown in Fig. 2c, the docking poses suggested that Formo could penetrate deeply into the pocket and form a hydrogen bond with the backbone nitrogen of Met793 in the hinge region in all 4 forms of EGFR. Moreover, the hydrogen bonding between Thr790 and the methoxyl of Formo was also critical. In the L858R/T790M mutated EGFR pocket, although Formo can form a hydrogen bond with the hinge region, it might take a different binding mode to avoid a stereo clash with Met790, which resulted in weaker binding affinity than the L858R single mutation. Additionally, both wild type and exon 19 deleted EGFRs form hydrogen bonding by Thr790 (bond lengths $3.3 \AA$ and $2.9 \AA$, respectively). However, the wild type EGFR made one "unnecessary" hydrogen bond between Lys716 and the ligand, which hindered Formo from deeper insertion into the pocket and resulted in less potency (Fig. 2d). These results suggested that Formo was a good hit for inhibition of EGFR, especially for the mutated types of exon 19 deletion, L858R single mutation, and L858R/ T790M mutation. We further conducted ATP competition assay with Formo-conjugated Sepharose 4B beads. The result showed that the binding between Formo and EGFR WT or mutants was decreased in the presence of ATP (Fig. 2e), indicating that interaction with Formo might disturb the interaction between EGFRs and ATP.

We next determined the effect of Formo on EGFR signaling in NSCLC cells. The IB data showed that EGFR phosphorylation was decreased in Formo treated HCC827, H3255, H1975, and A549 cells (Fig. 3a). Consistently, the phosphorylation of EGFR downstream targets, Akt (Ser473) and ERK1/2 (Thr202/Tyr204) were reduced robustly. In contrast, osimertinib only inhibited the activation of EGFR signaling in HCC827, H3255, and H1975, but not A549 cells (Fig. 3a). We further generated stable cell lines of $\mathrm{Ba} / \mathrm{F} 3$ cells carrying various EGFRs, including WT, L858R, L858R/T790M, and Del E746-A750 mutants. Our data showed that Formo inhibited the phosphorylation of EGFR, Akt, and ERK1/2 in these stable cell lines (Fig. 3b). Furthermore, osimertinib exhibited more robust inhibitory efficacy on EGFR signaling in L858R, L858R/T790M, and Del E746-A750 expressing $\mathrm{Ba} / \mathrm{F} 3$ cells when compare to Formo treatment. However, osimertinib failed to suppress EGFR signaling in WT EGFR expressing stable cells (Fig. 3b). These results indicate that Formo inhibits both WT and mutant EGFR signalings in NSCLC cells.

\section{Downregulation of Mcl-1 is required for Formo induced apoptosis in NSCLC cells}

Activation of EGFR signaling is required for maintaining cell growth and survival in EGFR activating mutation harbored NSCLC cells. Because Formo reduced cell viability significantly, we then determined whether treatment with Formo caused cell death. Pretreated with apoptosis inhibitor z-VAD-fmk, but not necroptosis inhibitor necrostatin-1 or GSK'872, attenuated Formo decreased cell viability (Fig. 4a). The IB result showed that Formo promoted the protein level of cleaved-PARP and -caspase 3 (Fig. 4b), further confirmed the activation of apoptosis signaling. Consistently, the activity of caspase 3 was significantly enhanced in Formo-treated NSCLC cells (Fig. 4c). The flow cytometry data revealed that Formo increased the population of apoptotic HCC827 cells dose-dependently (Fig. 4d, Supplementary Figure 2A). Moreover, Formo promoted the release of cytochrome $\mathrm{C}$ from mitochondria to the cytoplasm, and enhanced the mitochondrial localization of Bax (Fig. 4e), indicating the activation of intrinsic apoptosis signaling. 


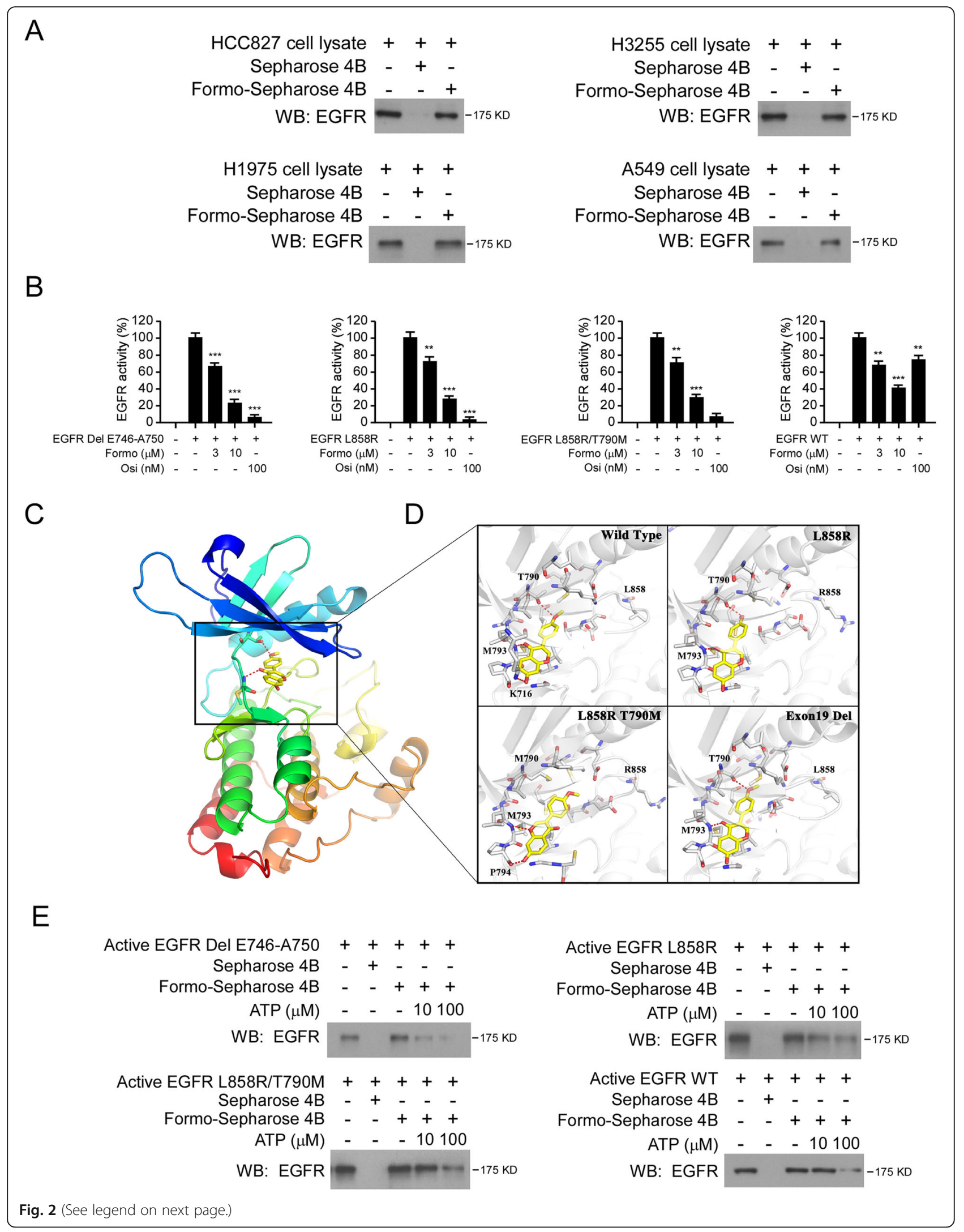


(See figure on previous page.)

Fig. 2 Formo inhibits the kinase activity of EGFR. a, Formo binds with EGFRs. Formo-Sepharose $4 B$ beads or Sepharose $4 B$ beads only was incubated with the whole-cell lysates $(500 \mathrm{\mu g})$ from HCC827, H3255, H1975, or A549 cells overnight at $4{ }^{\circ} \mathrm{C}$, and subjected to immunoblotting (IB) analysis. b, Formo suppresses the activity of EGFR wild type (WT) and EGFR activating mutants in vitro. Osi serves as a positive or negative control. ${ }^{* *} p<0.01$, ${ }^{* *} p<0.001$. $\mathbf{c}$ and $\mathbf{d}$, Binding modes of Formo with WT and mutated EGFRs predicted by molecular docking. $\mathbf{c}$, Cartoon representation of the Formo binding pocket in EGFR. $\mathbf{d}$, Different binding modes of Formo with 4 types of EGFR. The ligands were shown in yellow sticks, while proteins were depicted in cartoon representation with key residues indicated as gray sticks and labeled. Hydrogen bonds were shown as red dashed lines. e, In vitro ATP competitive binding of Formo and EGFR WT or EGFR activating mutants, were examined by pulldown and ATP competition assays

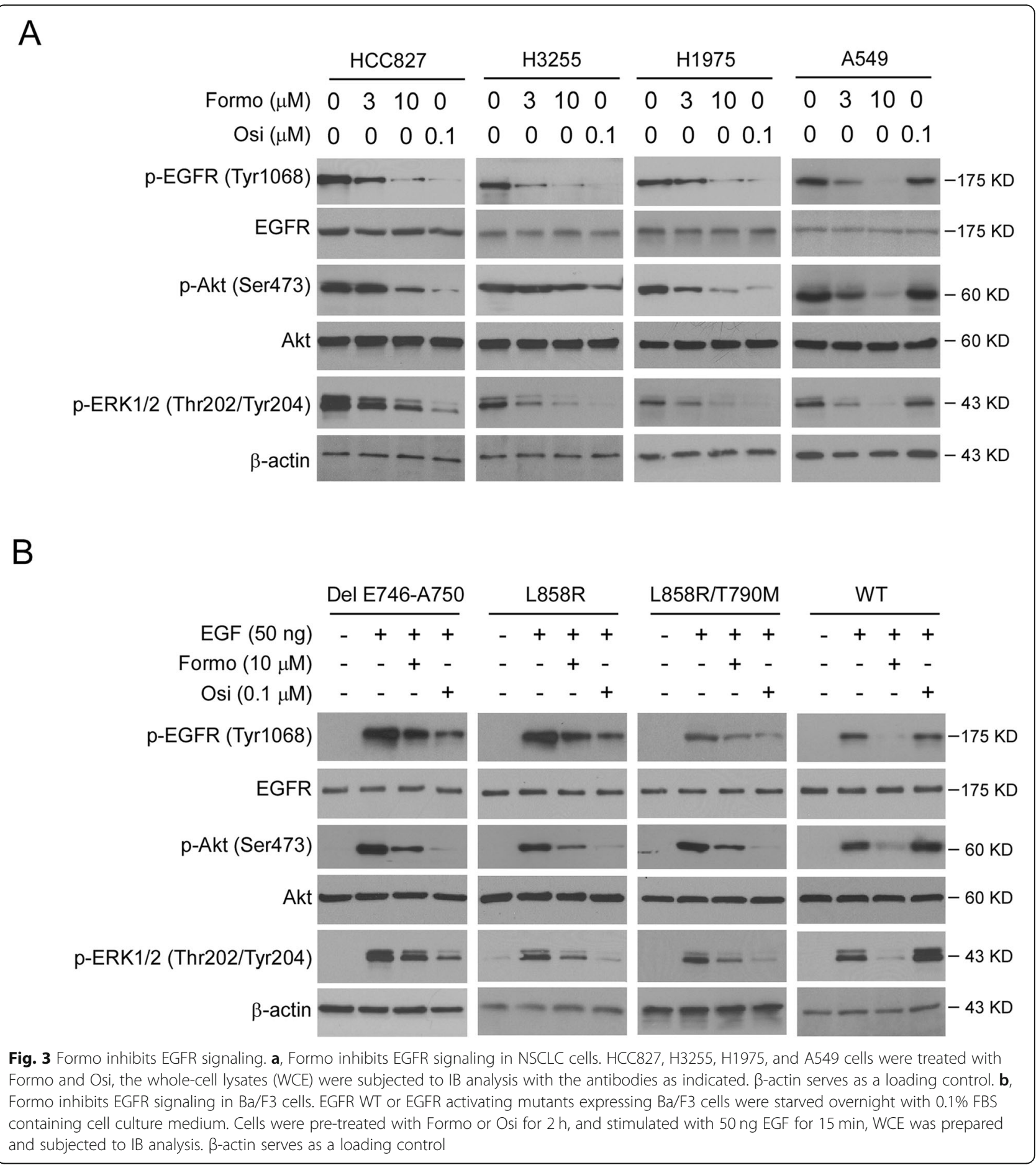




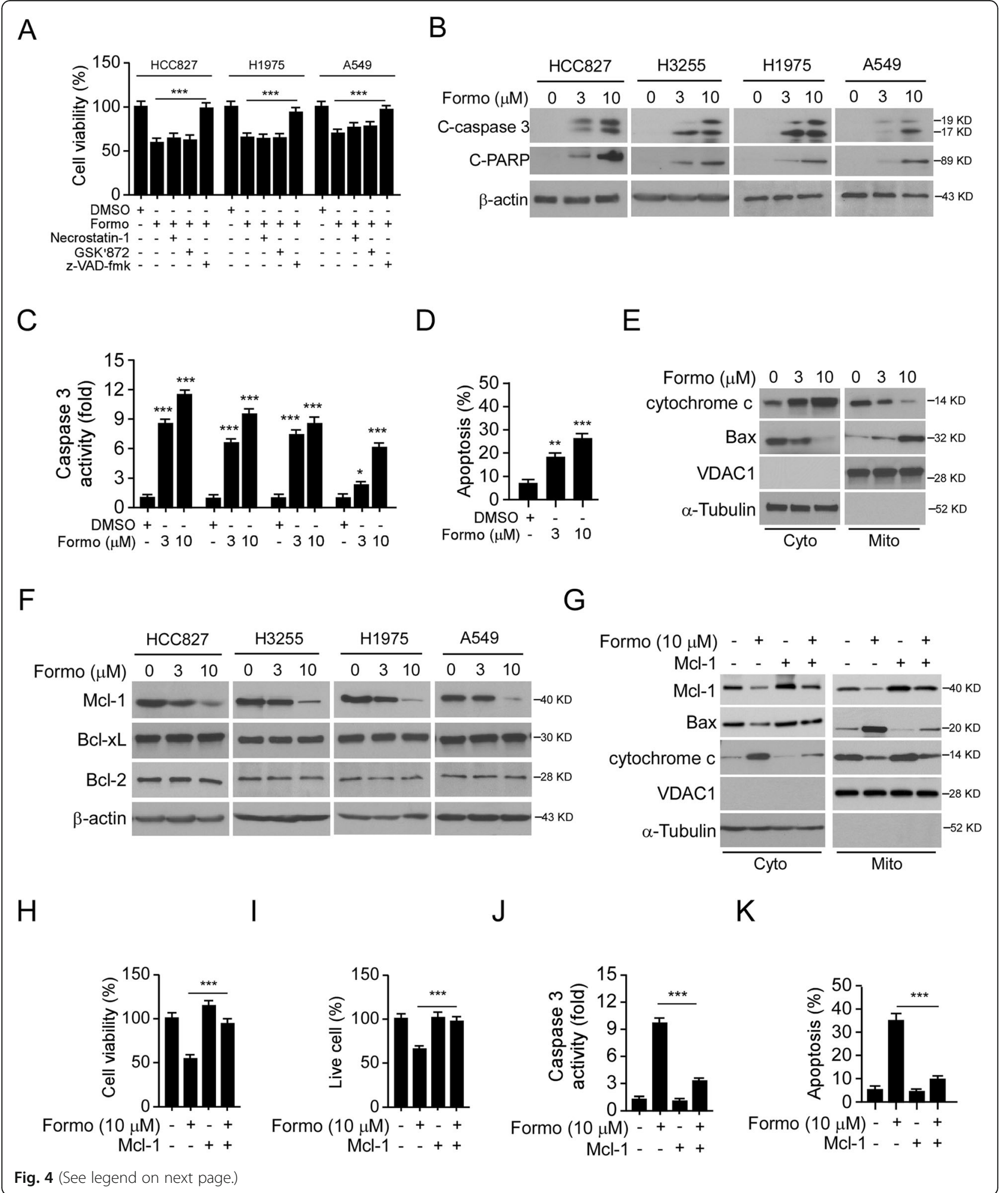




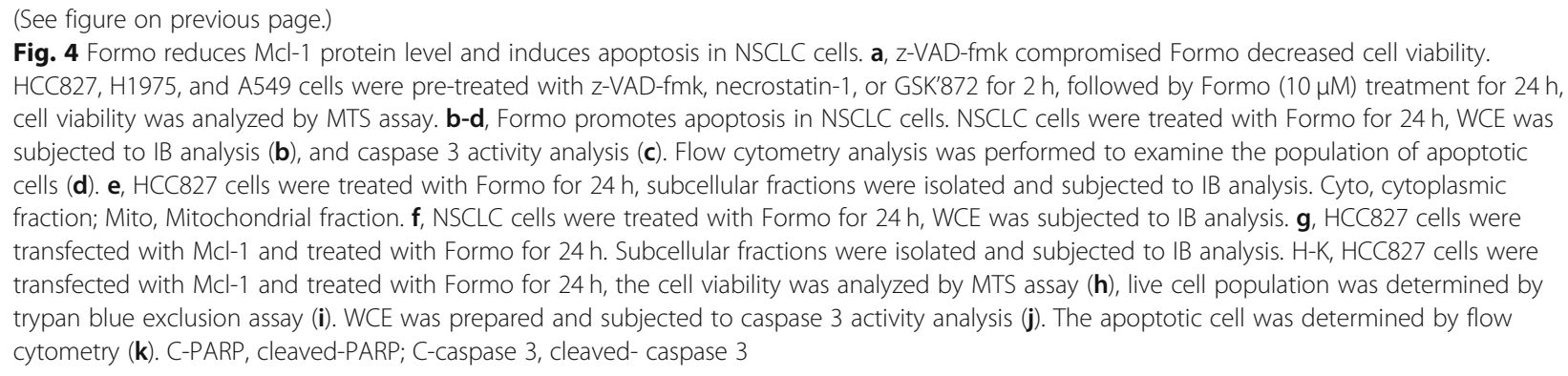

We next investigated whether Formo-induced intrinsic apoptosis is caused by the deregulation of pro-survival Bcl-2 family members. The IB results indicated that the protein level of $\mathrm{Mcl}-1$, but not the $\mathrm{Bcl}-2$ or $\mathrm{Bcl}-\mathrm{xL}$, was reduced in response to Formo treatment (Fig. 4f). To determine whether the downregulation of Mcl-1 led to apoptosis in Formo-treated cells, we overexpressed Mcl1 in HCC827 cells. Our data showed that transient transfection of Mcl-1 attenuated Formo promoted cytochrome $\mathrm{C}$ release and the mitochondrial localization of Bax (Fig. 4g). Furthermore, ectopic overexpression of Mcl-1 increased cell viability (Fig. 4h) and the live cell population (Fig. 4i) when compare to Formo treatment cells. Consistently, Formo-promoted caspase 3 activation (Fig. 4j) and apoptosis (Fig. 4k, Supplementary Figure 2B) were compromised by Mcl-1 transfection. These results indicate that Formo decreased the protein level of Mcl-1 and induced mitochondrial-associated apoptosis in NSCLC cells.

\section{Suppression of Akt is required for Formo-induced Mcl-1 downregulation}

ERK1/2 and Akt signalings are two major downstream oncogenic pathways of EGFR kinase. Because Formo inhibited EGFR activity and reduced Mcl-1 protein level, we therefore determined which signaling is required for Mcl-1 expression in NSCLC cells. By treating with the MAPK/ERK1/2 (PD98059) and PI3K/Akt (LY294002) pathway inhibitors, we found that suppression of Akt, but not ERK1/2, decreased Mcl-1 robustly (Fig. 5a). The silencing of Akt1 by siRNA reduced the Mcl-1 protein level and enhanced Formo-mediated Mcl-1 downregulation and cleaved-caspase 3 expression (Fig. 5b). Furthermore, the population of live cells was decreased in Formo-treated Akt knockdown cells (Supplementary Figure $3 \mathrm{~A}$ ), and the Caspase 3 activity was enhanced consistently (Supplementary Figure 3B). Moreover, ectopic overexpression of constitutively activated Akt1 (Myr-Akt) compromised Formo-induced Mcl-1 reduction (Fig. 5c). Interestingly, suppression of Akt downstream kinase GSK3 $\beta$ by small molecule inhibitor SB216763, restored Mcl-1 expression and decreased the protein of cleaved-caspase 3 and cleaved-PARP after
Formo treatment (Fig. 5d), indicating that the reduction of Mcl-1 is dependent on Formo-activated GSK3 $\beta$ kinase. Likewise, depletion of GSK3 $\beta$ by shRNA increased Mcl-1 protein level and compromised Formo-induced apoptosis (Fig. 5e). Phosphorylation of Ser9 is required for Akt-mediated GSK3 $\beta$ inhibition, and loss of Ser9 phosphorylation activates GSK3 $\beta$ kinase [28]. We next generated the Ser9 to Ala9 (S9A) mutant and found that ectopic overexpression of GSK-3 $\beta$ S9A promoted Formo-induced Mcl-1 reduction and enhanced the expression of cleaved-PARP and -caspase 3 (Fig. 5f). These results suggest that downregulation of Akt and activation of GSK- $3 \beta$ is required for Formo-induced Mcl-1 reduction and apoptosis induction.

\section{Formo promotes FBW7-mediated Mcl-1 ubiquitination}

To better understand how GSK-3 $\beta$ downregulates Mcl-1 protein level, we first examined the effect of Formo on Mcl-1 transcription. Our data indicated that Formo did not inhibit Mcl-1 mRNA level significantly (Fig. 6a). However, treated with proteasome inhibitor MG132 restored Mcl-1 expression even in the presence of Formo (Fig. 6b). Moreover, treatment with Formo shortens Mcl-1 half-life from around 3.5 $\mathrm{h}$ to $1.5 \mathrm{~h}$ (Fig. 6c). These results suggest that Formo cause Mcl-1 ubiquitination and degradation. Indeed, the IB analysis revealed that treatment with Formo increased Mcl-1 endogenous polyubiquitination robustly (Fig. 6d). Phosphorylation of Mcl-1 on S159 reduced Mcl-1 stability. Our data revealed that Mcl-1 S159 phosphorylation was increased upon Formo treatment in NSCLC cells (Fig. 6e). The E3 ligase $\mathrm{SCF}^{\mathrm{Fbw}}$ 7 promotes Mcl-1 ubiquitination in a GSK3 $\beta$ mediated Mcl-1 phosphorylation-dependent manner. We speculated that FBW7 is required for Formo enhanced Mcl-1 ubiquitination. Indeed, treatment with GSK3 $\beta$ inhibitor SB216763 reduced Mcl-1 S159 phosphorylation and increased Mcl-1 protein level (Supplementary Figure 4). Furthermore, the interaction between Mcl-1 and FBW7 was enhanced by Formo treatment (Fig. 6f). To further confirm that FBW7 plays a crucial role in Formo-induced Mcl-1 degradation, we constructed FBW7 knockdown stable cell 


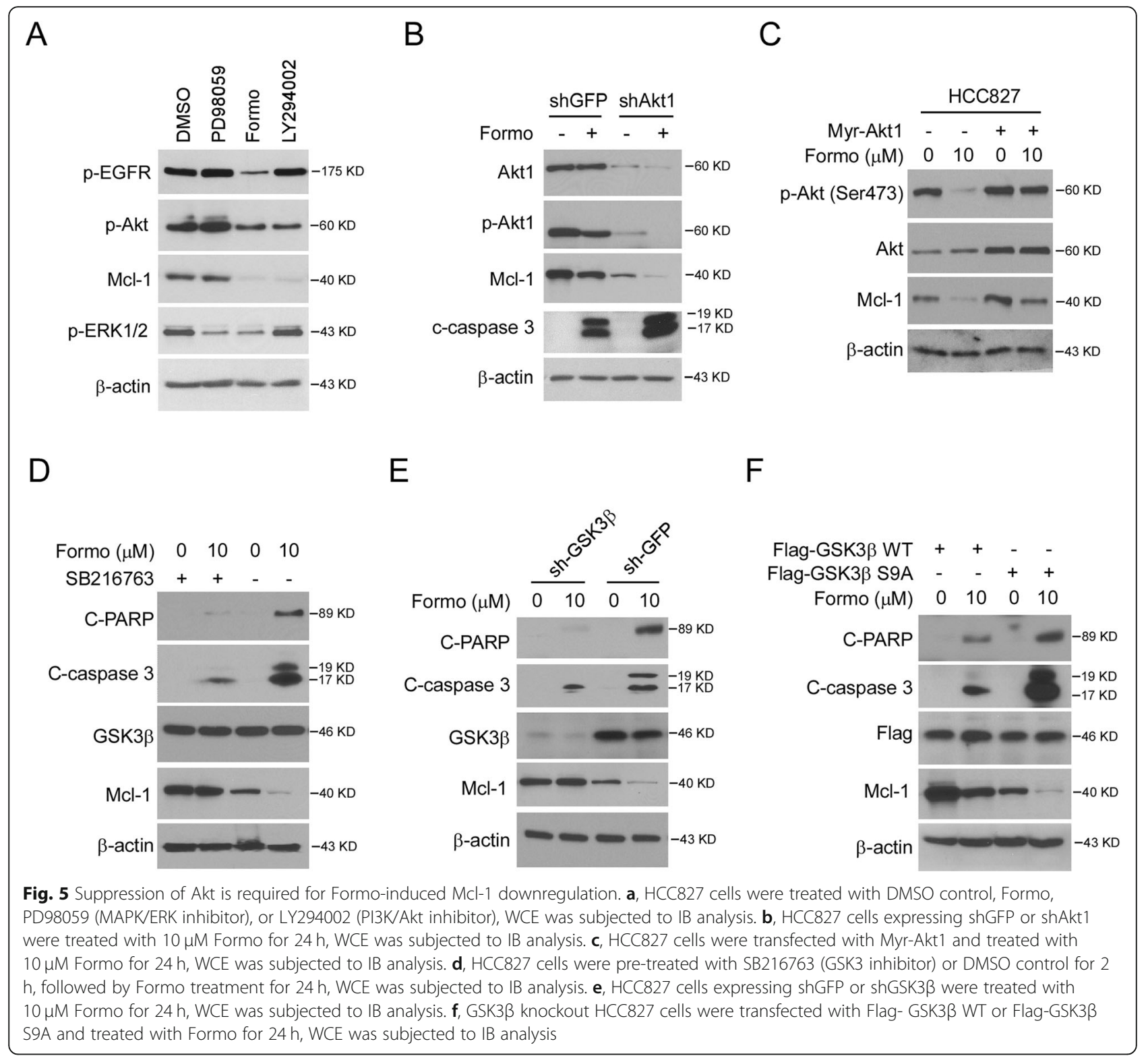

line. The result revealed that Formo promoted Mcl-1 ubiquitination in FBW7 proficient HCC827 cells, but failed to do so in FBW7 deficient cells (Fig. 6g). Consistently, depletion of FBW7 by shRNA increased cell viability even in the presence of Formo (Fig. 6h). These data support the notion that FBW7 is required for Formo-induced Mcl-1 ubiquitination and degradation in NSCLC cells.

\section{Formo inhibits xenograft tumor growth in vivo}

We next examined the in vivo anti-tumor effect of Formo using the xenograft mouse model. The results revealed that once-daily dosing of osimertinib only delayed in vivo tumor development in the HCC827, H3255, and H1975 xenografts (Fig. 7a-f, Supplementary Figure 5A-
C) which harbored EGFR activating mutation. In contrast, Formo suppressed both EGFR mutant and WT tumors, including HCC827, H3255, H1975, A549, and H1299-derived xenograft (Fig. 7a-h, Supplementary Figure 5A-G). Osimertinib treated A549 and H1299derived xenograft tumors exhibited similar tumor volumes and tumor weight as the vehicle-treated group. In contrast, Formo reduced tumor sizes significantly at the treatment endpoint than that of the vehicle treatment (Fig. 7g-h, Supplementary Figure 5D-G). However, osimertinib possessed a more potent anti-tumor efficacy than Formo in EGFR activating mutation xenografts, including HCC827, H3255, and H1975 tumors, and the tumor volume was less than $100 \mathrm{~mm}^{3}$ at the endpoint. We further determined the inhibitory effect of Formo on 


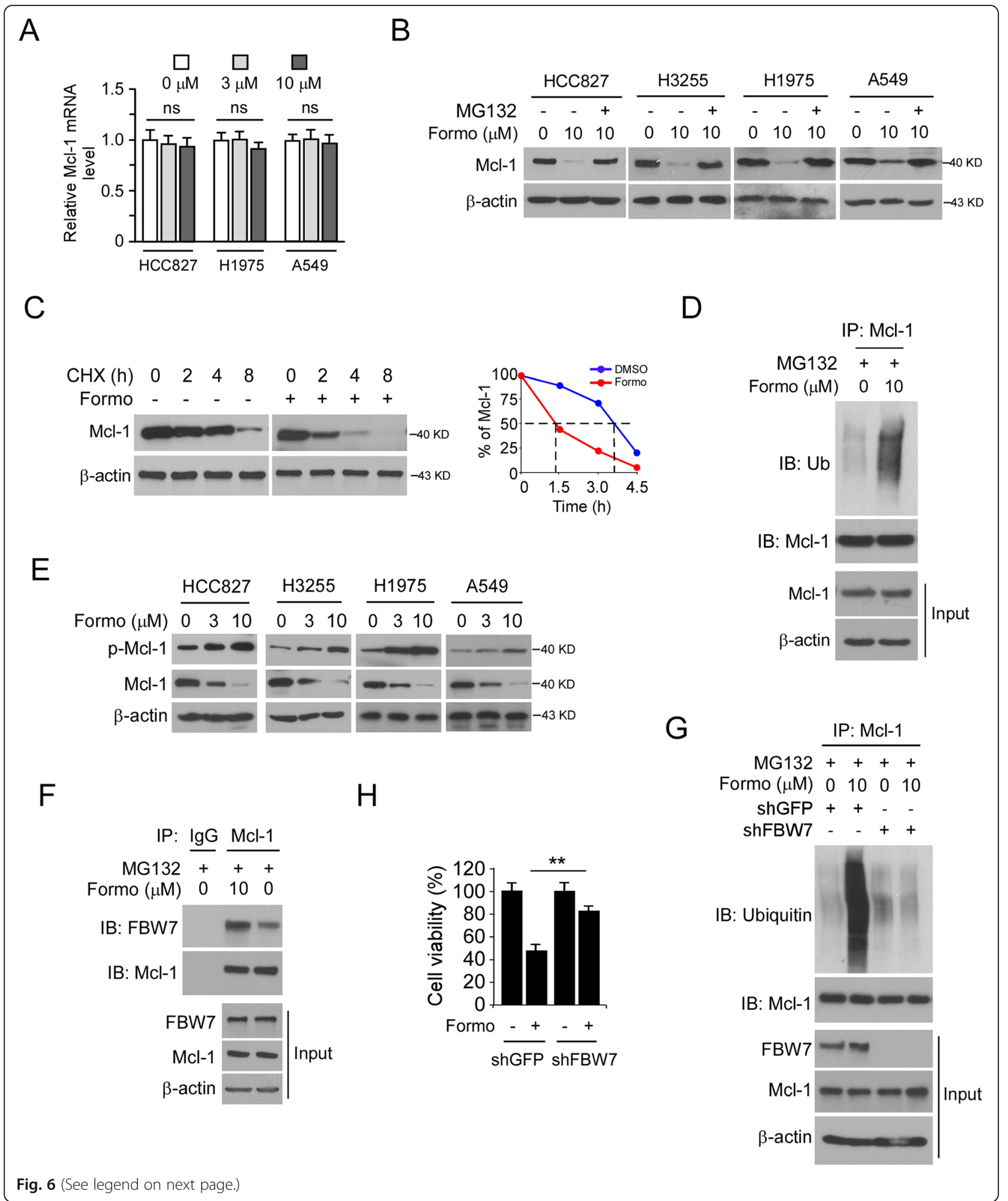




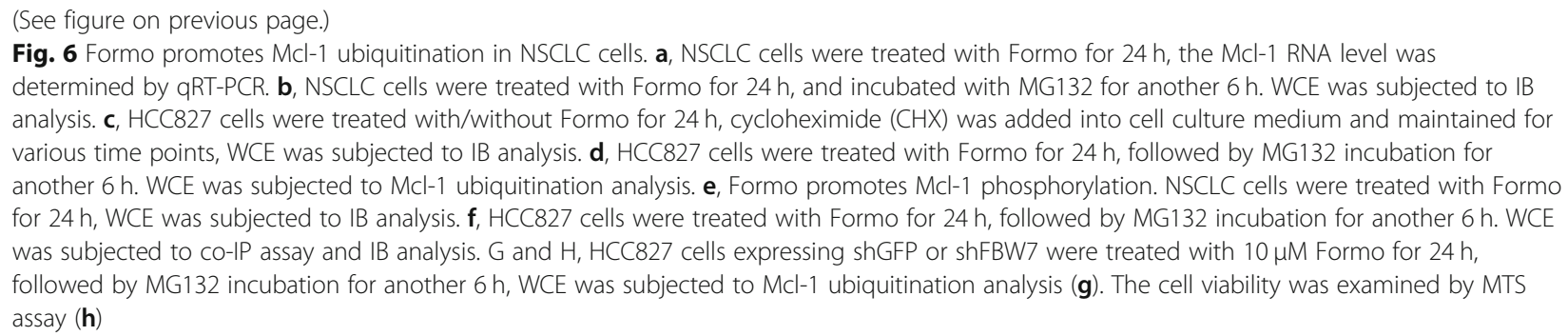

osimertinib acquired resistant HCC827 OR cells in vivo. As shown in Supplementary Figure 6H- J, Formo, but not osimertinib, reduced tumor volume and tumor weight significantly. We further performed IHC staining to examine the expression of Ki67, p-EGFR, p-Akt, and Mcl-1 in HCC827-derived xenograft tumors. The results showed that both Formo and osimertinib decreased the population of Ki67 positive cells (Fig. 7i and j). Moreover, the staining of p-EGFR, p-Akt, and Mcl-1 was reduced significantly in the Formo or osimertinib treated group (Fig. $7 \mathrm{i}$ and $\mathrm{j}$ ). The IB data revealed that treatment with either Formo or osimertinib decreased the protein level of p-EGFR, p-Akt, and Mcl-1 in xenograft tumor tissues (Fig. 7k). These results consistent with our in vitro findings and further confirmed the anti-tumor effect of Formo in vivo.

To further evaluate the in vivo toxicity of Formo, we monitored mouse body weight with Formo treatment. Our data revealed that both Formo and osimertinib did not cause a significant weight loss at the current dose (Supplementary Figure 6A). The blood analysis results showed that the RBC and WBC count, as well as the AST, ALT, BUN, and Hb, were similar in Formo, osimertinib, and the vehicle-treated mice (Supplementary Figure 6B). These data indicate that Formo was welltolerated and no significant toxicity to vital organs in vivo.

\section{Discussion}

EGFR activating mutations serve as driver mutations and play a crucial role in the tumorigenesis of NSCLC. Therapeutic strategies using TKI to inhibit EGFR signaling have become an effective approach for these patients $[1,29]$. However, most patients relapsed on TKIs due to acquired resistance. It is generally believed that hyperactivation of Akt and ERK1/2 signaling are the most common mechanisms of resistance to multiple targeted therapeutics [30]. Thus, identification of novel small molecule inhibitors to overcome primary or acquired TKI resistance is still an urgent need in NSCLC treatment. In this study, with natural compound screening, we identified Formo acted as a potential EGFR inhibitor to suppress NSCLC cells. Our data indicated that Formo docked into the EGFR ATP-binding pocket and decreased EGFR kinase activity. The in vitro and in vivo data further confirmed this inhibitory effect. Moreover, Formo reduced Mcl-1 protein level in an Akt kinasedependent manner and promoted mitochondrial apoptosis. Our data extend the understanding of the Formomediated anti-tumor mechanism and suggest that suppression of both EGFR signaling and downstream oncoprotein is an alternative strategy to enhance the efficacy of the anti-tumor agent.

As the unique pro-survival Bcl-2 family member, Mcl1 is required for maintaining cell growth and survival of NSCLC, prostate, colorectal, liver, and gastric cancer cells $[10,31]$. Mcl-1 is a short half-life protein, and the expression of Mcl-1 is regulated at multiple levels, including transcription, translation, and post-translation [32]. Mcl-1 inhibits mitochondrial outer membrane permeabilization (MOMP) and suppresses cytochrome c release from mitochondria to antagonist apoptosis. Thus, overexpression of $\mathrm{Mcl}-1$ was frequently observed in therapeutic resistant tumors. NF- $\mathrm{KB}$ dependent upregulation of Mcl-1 confers chemo/radiotherapy resistance in NSCLC and esophageal carcinoma [33]. The reduction of Mcl-1 protein by GSK3 $\beta-\beta$-TrCP axis-mediated Mcl1 ubiquitination and degradation enhances tumor-killing efficacy of chemotherapy agents [34]. Furthermore, degradation of Mcl-1 in colon cancer is required for targeted therapeutics induced tumor suppression [35]. Recent studies revealed that the decrease of Mcl-1 plays a crucial role in TKI or other targets therapy-mediated tumor suppression. For example, TKI promotes $\mathrm{Mcl}-1$ degradation and, in combination with $\mathrm{Bcl}-\mathrm{XL} / \mathrm{Bcl} 2$ inhibitors, induced apoptosis in cancer cells [36]. Inhibition of EGFR by TKI, erlotinib, disrupts the interaction between Bim and Mcl-1 and sensitizes tumor cells to ABT-737 treatment [37]. Degradation of Mcl-1 overcome acquired resistance to osimertinib in EGFRmutant lung cancer $[38,39]$. These reports indicate that target Mcl-1 is a promising anti-tumor strategy for clinical treatment. However, there is no Mcl-1 inhibitors have been approved currently, especially the small compound, which can directly reduce the Mcl- 1 protein level by ubiquitination-mediated degradation [40]. Our results revealed that Formo is a well tolerate compound that decreased Mcl-1 expression through ubiquitination- 


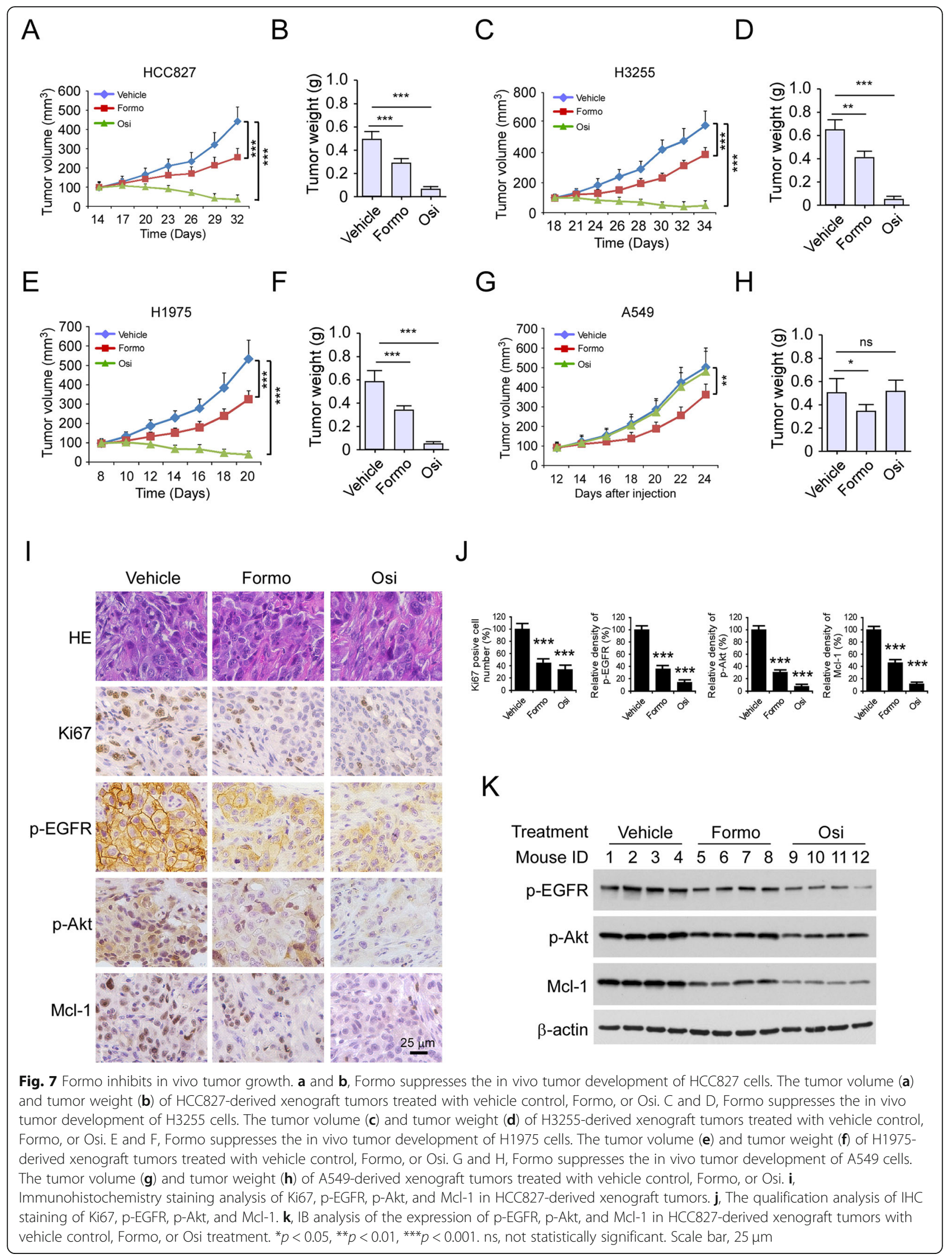


dependent degradation. Formo enhances the interaction between Mcl-1 and E3 ligase, therefore shortens Mcl-1 half-life and promotes protein destruction. These findings offer an alternative strategy to degrade the nonenzymatic activity oncoproteins through ubiquitination.

Currently, four different E3 ligases have been identified as Mcl-1 negative regulators to attenuate Mcl-1 stability, including $\beta$-Trcp [34], Trim17 [41], Mule [42], and FBW7 [43]. In contrast, multiple deubiquitinase, such as DUB3 [44], USP9X [45], and USP13 [46], were required for reversing Mcl-1 ubiquitination. In this study, we found that Formo-induced Mcl-1 degradation in an FBW7-dependent manner, depletion of FBW7 compromised Formo-promoted Mcl-1 ubiquitination. Importantly, we demonstrated that Formo suppresses EGFRAkt signaling, which in turn activates GSK3 $\beta$ and eventually enhanced GSK3 $\beta$-mediated Mcl-1 phosphorylation and FBW7-mediated degradation. Indeed, depletion of FBW7 causes the upregulation of Mcl-1 and confers TKI resistance in PC9 cells [47]. Our data are consistent with the previous reports and indicate that the decrease of Mcl-1 is a promising strategy to overcome TKI resistance in NSCLC treatment.

Formo is a flavonoid which originates mainly from red clovers and the Chinese herb Astragalus membranaceus. Accumulating evidence suggests that Formo was a multiple kinase inhibitor. A panel of kinases was identified as the protein targets of Formo, including MAPK (ERK1/2, P38), PI3K/Akt, VEGFR, FGFR, and mTOR $[14,15]$. Our data showed that Formo suppressed EGFR signaling and decreased the protein level of Mcl-1. However, we cannot exclude the possibility that other oncogenic signalings are involved in Formo-mediated antitumor activity. Currently, numerous preclinical investigations have demonstrated that Formo exhibits chemopreventive and therapeutic potentials in multiple cancer models. The combination with Formo, significantly enhanced the anti-tumor effect of chemotherapeutic agents in a wide range of human cancers [14, 15]. Our data showed that Formo reduced the in vivo tumor growth in both EGFR WT and mutant xenograft tumors. Importantly, Formo is well-tolerated in vivo and exhibited no significant toxicity to vital organs, indicating that Formo is a potential anti-tumor candidate compound for EGFR WT and activating mutation NSCLC treatment.

\section{Conclusion}

Overall, this study demonstrated that Formo acts as an inhibitor for the EGFR-Akt axis, and promotes FBW7mediated Mcl-1 ubiquitination is required for the antitumor activity of Formo both in vitro and in vivo. Our findings suggest that targeting protein degradation might a new option for cancer treatment.

\section{Supplementary information}

Supplementary information accompanies this paper at https://doi.org/10. 1186/s13046-020-01566-2.

Additional file 1: Figure S1. The effect of formononetin (Formo) on anchorage-independent cell growth of NSCLC cells. H3255 (A), H1975 (B), A549 (C), H1299 (D), and HCC827 OR (E) cells were treated with Formo or osimertinib (Osi), anchorage-independent cell growth was analyzed by soft agar assay. Scale bar, 200 um. Osi, osimertinib. Figure S2. Flow cytometry analysis of apoptotic cell population in Formo-treated HCC827 cells. A, HCC827 cells were treated with Formo for $24 \mathrm{~h}$, apoptotic cells were analyzed by flow cytometry. B, HCC827 cells were transfected with Mcl- 1 and treated with Formo $(10 \mu \mathrm{M})$ for $24 \mathrm{~h}$, apoptotic cells were analyzed by flow cytometry. Figure S3. Akt inhibition or depletion promotes Formo-induced apoptosis. A, HCC827 cells expressing shGFP or shAkt1 were treated with $10 \mu \mathrm{M}$ Formo for $24 \mathrm{~h}$, the live cell population was determined by trypan blue exclusion assay. B, HCC827 cells expressing shGFP or shAkt1 were treated with $10 \mu \mathrm{M}$ Formo for $24 \mathrm{~h}$, whole cell extract was prepared and subjected to caspase 3 activity analysis. ${ }^{* *}, p<$ 0.001 . Figure S4. GSK3 $\beta$ regulates $\mathrm{Mcl}-1$ phosphorylation and expression. HCC827 cells were treated with SB216763 for 24 h, whole cell extract was subjected to immunoblotting (IB) analysis. Figure S5. Formo inhibits the in vivo tumor growth of NSCLC cells. A-D, The image of HCC827- (A), H3255- (B), H1975- (C), and A549 (D)-derived xenograft tumors with the vehicle control, Formo, or Osi treatment. E-G, Formo inhibits the in vivo tumor growth of $\mathrm{H} 1299$ cells. Tumor volume (E), the image of tumor mass (F), and tumor weight (G) of $\mathrm{H} 1299$ xenograft tumors treated with the vehicle control, Formo, or Osi. $\mathrm{H}$-J, Formo inhibits the in vivo tumor growth of HCC827 OR cells. Tumor volume $(\mathrm{H})$, the image of tumor mass $(\mathrm{I})$, and tumor weight $(\mathrm{J})$ of HCC827 OR xenograft tumors treated with the vehicle control, Formo, or Osi. ${ }^{* *}, p<0.01 ;{ }^{* * *}, p<0.001$. ns, not statistically significant. Scale bar, $1 \mathrm{~cm}$. Figure S6. Toxicity analysis for treatment with Formo and Osi. A, Body weight of HCC827 xenograft tumor bearing mice with the vehicle, Formo, or Osi treatment. B, Blood analysis of mice with the vehicle, Formo, or Osi treatment. ns, not statistically significant. Table S1. Screened compound list.

\section{Abbreviation}

EGFR: Epidermal growth factor receptor; NSCLC: Non-small cell lung cancer; Mcl-1: Myeloid cell leukemia sequence 1; Formo: Formononetin; TKl: Tyrosine kinase inhibitors; Osi: Osimertinib; PFS: Progression-free survival; WT: Wild type; PDB: Protein Data Bank; DOPE: Discrete Optimized Protein Energy; ALK: Anaplastic lymphoma kinase; MOMP: Mitochondrial outer membrane permeabilization; IB: Immunoblotting; IHC: Immunohistochemical staining; CHX: Cycloheximide; Cyto: Cytoplasmic fraction; Mito: Mitochondrial fraction; RBC: Red blood cells; WBC: White blood cells; Hb: Hemoglobin; ALT: Alanine aminotransferase; AST: Aspartate aminotransferase; BUN: Blood urea nitrogen

\section{Acknowledgments}

We would like to thank Shiming Tan at the Third Xiangya Hospital for technical assistance.

\section{Authors' contributions}

Conception and design: $X Y, F G, W L$. Development of methodology: XY, FG, WL. Acquisition of data: $X Y, F G, W L, M L, L Z, W L$. Analysis and interpretation of data (statistical analysis, biostatistics, computational analysis): XY, FG, WL, $M L, L Z, W L$. Writing, review, and revision of the manuscript: $X Y, F G, W L$. Administrative, technical or material support $X Y, F G, W L, M L, L Z, W L$. Supervision: $X Y, F G, M L, W L$. All authors read and approved the final manuscript.

\section{Funding}

This work was supported by the National Natural Science Foundation of China (No.81904262, and No.81972837), the Natural Science Foundation of Hunan Province (2018JJ3787, 2018JJ2604, 2019JJ50682).

Availability of data and materials Materials are available upon request. 


\section{Ethics approval and consent to participate}

The animal experiments were approved by the Medical Research Animal Ethics Committee, Central South University, China.

\section{Consent for publication}

Not applicable.

\section{Competing interests}

The authors declare that they have no conflict of interest.

\section{Author details}

'Cell Transplantation and Gene Therapy Institute, The Third Xiangya Hospital, Central South University, Changsha, Hunan 410013, P.R. China. ${ }^{2}$ Shandong Lvdu Bio-Industry Co Ltd, Binzhou, Shandong 256600, P.R. China.

${ }^{3}$ Department of Ultrasonography, The Third Xiangya Hospital of Central South University, Changsha, Hunan 410013, P.R. China. ${ }^{4}$ Department of Radiology, The Third Xiangya Hospital of Central South University, Changsha, Hunan 410013, P.R. China. ${ }^{5}$ Department of Pathology, Xiangya Hospital of Central South University, Changsha, Hunan 410008, P.R. China. ${ }^{6}$ Department of Pathology, Hunan Cancer Hospital, Changsha, Hunan 410013, P.R. China. ${ }^{7}$ Changsha Stomatological Hospital, Changsha, Hunan 410004, P.R. China. ${ }^{8}$ School of Stomatology, Hunan University of Chinese Medicine, Changsha, Hunan 410208, P.R. China.

Received: 25 January 2020 Accepted: 26 March 2020 Published online: 10 April 2020

\section{References}

1. Arbour KC, Riely GJ. Systemic therapy for locally advanced and metastatic non-small cell lung Cancer: a review. JAMA. 2019;322(8):764-74.

2. Tartarone A, Lerose R. Clinical approaches to treat patients with non-small cell lung cancer and epidermal growth factor receptor tyrosine kinase inhibitor acquired resistance. Ther Adv Respir Dis. 2015:9(5):242-50.

3. Gelatti ACZ, Drilon A, Santini FC. Optimizing the sequencing of tyrosine kinase inhibitors (TKIs) in epidermal growth factor receptor (EGFR) mutationpositive non-small cell lung cancer (NSCLC). Lung Cancer. 2019;137:113-22.

4. Kobayashi S, Boggon TJ, Dayaram T, Janne PA, Kocher O, Meyerson M, et al. EGFR mutation and resistance of non-small-cell lung cancer to gefitinib. $\mathrm{N}$ Engl J Med. 2005;352(8):786-92.

5. Engelman JA, Zejnullahu K, Mitsudomi T, Song Y, Hyland C, Park JO, et al. MET amplification leads to gefitinib resistance in lung cancer by activating ERBB3 signaling. Science. 2007;316(5827):1039-43.

6. Leonetti A, Sharma S, Minari R, Perego P, Giovannetti E, Tiseo M. Resistance mechanisms to osimertinib in EGFR-mutated non-small cell lung cancer. $\mathrm{Br}$ J Cancer. 2019;121(9):725-37.

7. Mehlman C, Cadranel J, Rousseau-Bussac G, Lacave R, Pujals A, Girard N et al. Resistance mechanisms to osimertinib in EGFR-mutated advanced non-small-cell lung cancer: a multicentric retrospective French study. Lung Cancer. 2019;137:149-56

8. Lai GGY, Lim TH, Lim J, Liew PJR, Kwang XL, Nahar R, et al. Clonal MET amplification as a determinant of tyrosine kinase inhibitor resistance in epidermal growth factor receptor-mutant non-small-cell lung Cancer. J Clin Oncol. 2019:37(11):876-84.

9. Senichkin W, Streletskaia AY, Zhivotovsky B, Kopeina GS. Molecular comprehension of Mcl-1: from gene structure to Cancer therapy. Trends Cell Biol. 2019;29(7):549-62.

10. Xiang $W$, Yang CY, Bai L. MCL-1 inhibition in cancer treatment. Onco Targets Ther. 2018;11:7301-14.

11. Yamaguchi R, Lartigue L, Perkins G. Targeting Mcl-1 and other $\mathrm{BCl}-2$ family member proteins in cancer therapy. Pharmacol Ther. 2019;195:13-20.

12. Booy EP, Henson ES, Gibson SB. Epidermal growth factor regulates Mcl-1 expression through the MAPK-Elk-1 signalling pathway contributing to cell survival in breast cancer. Oncogene. 2011;30(20):2367-78.

13. Song KA, Hosono Y, Turner C, Jacob S, Lochmann TL, Murakami Y, et al. Increased synthesis of MCL-1 protein underlies initial survival of EGFRmutant lung Cancer to EGFR inhibitors and provides a novel drug target. Clin Cancer Res. 2018;24(22):5658-72.

14. Tay KC, Tan LT, Chan CK, Hong SL, Chan KG, Yap WH, et al. Formononetin: a review of its anticancer potentials and mechanisms. Front Pharmacol. 2019;10:820.
15. Ong SKL, Shanmugam MK, Fan L, Fraser SE, Arfuso F, Ahn KS, et al. Focus on Formononetin: Anticancer Potential and Molecular Targets. Cancers (Basel). 2019;11:5

16. Yang C, Xie Q, Zeng X, Tao N, Xu Y, Chen Y, et al. Novel hybrids of podophyllotoxin and formononetin inhibit the growth, migration and invasion of lung cancer cells. Bioorg Chem. 2019;85:445-54.

17. Zhang L, Gong Y, Wang S, Gao F. Anti-colorectal Cancer mechanisms of Formononetin identified by network pharmacological approach. Med Sci Monit. 2019;25:7709-14.

18. Xin M, Wang Y, Ren Q, Guo Y. Formononetin and metformin act synergistically to inhibit growth of MCF-7 breast cancer cells in vitro. Biomed Pharmacother. 2019;109:2084-9.

19. Yao JN, Zhang XX, Zhang YZ, Li JH, Zhao DY, Gao B, et al. Discovery and anticancer evaluation of a formononetin derivative against gastric cancer SGC7901 cells. Investig New Drugs. 2019:37(6):1300-8.

20. Zhou L, Yu X, Li M, Gong G, Liu W, Li T, et al. Cdh1-mediated Skp2 degradation by dioscin reprogrammes aerobic glycolysis and inhibits colorectal cancer cells growth. EBioMedicine. 2019;51:102570.

21. Li W, Yu X, Xia Z, Yu X, Xie L, Ma X, et al. Repression of Noxa by Bmi1 contributes to deguelin-induced apoptosis in non-small cell lung cancer cells. J Cell Mol Med. 2018;22(12):6213-27.

22. Zhang Y, Yao K, Shi C, Jiang Y, Liu K, Zhao S, et al. 244-MPT overcomes gefitinib resistance in non-small cell lung cancer cells. Oncotarget. 2015; 6(42):44274-88.

23. Sheng Y, Li W, Zhu F, Liu K, Chen H, Yao K, et al. 3,6,2',4',5'Pentahydroxyflavone, an orally bioavailable multiple protein kinase inhibitor, overcomes gefitinib resistance in non-small cell lung cancer. J Biol Chem. 2014;289(41):28192-201.

24. Sali A, Blundell TL. Comparative protein modelling by satisfaction of spatial restraints. J Mol Biol. 1993:234(3):779-815.

25. Berman HM, Westbrook J, Feng Z, Gilliland G, Bhat TN, Weissig H, et al. The Protein Data Bank. Nucleic Acids Res. 2000;28(1):235-42.

26. Yu X, Wang R, Zhang Y, Zhou L, Wang W, Liu H, et al. Skp2-mediated ubiquitination and mitochondrial localization of Akt drive tumor growth and chemoresistance to cisplatin. Oncogene. 2019;38(50):7457-72.

27. Liu H, Li W, Yu X, Gao F, Duan Z, Ma X, et al. EZH2-mediated Puma gene repression regulates non-small cell lung cancer cell proliferation and cisplatin-induced apoptosis. Oncotarget. 2016:7(35):56338-54

28. Cross DA, Alessi DR, Cohen P, Andjelkovich M, Hemmings BA. Inhibition of glycogen synthase kinase-3 by insulin mediated by protein kinase B. Nature. 1995;378(6559):785-9.

29. Skoulidis F, Heymach JV. Co-occurring genomic alterations in non-small-cell lung cancer biology and therapy. Nat Rev Cancer. 2019;19(9):495-509.

30. Santoni-Rugiu E, Melchior LC, Urbanska EM, Jakobsen JN, Stricker K, Grauslund M, et al. Intrinsic resistance to EGFR-Tyrosine Kinase Inhibitors in EGFR-Mutant Non-Small Cell Lung Cancer: Differences and Similarities with Acquired Resistance. Cancers (Basel). 2019;11:7.

31. Akgul C. Mcl-1 is a potential therapeutic target in multiple types of cancer. Cell Mol Life Sci. 2009:66(8):1326-36.

32. Senichkin W, Streletskaia AY, Gorbunova AS, Zhivotovsky B, Kopeina GS Saga of Mcl-1: regulation from transcription to degradation. Cell Death Differ. 2020;1:1.

33. Whitsett TG, Mathews IT, Cardone MH, Lena RJ, Pierceall WE, Bittner M, et al. Mcl-1 mediates TWEAK/Fn14-induced non-small cell lung cancer survival and therapeutic response. Mol Cancer Res. 2014:12(4):550-9.

34. Ding Q, He X, Hsu JM, Xia W, Chen CT, Li LY, et al. Degradation of MCl-1 by beta-TrCP mediates glycogen synthase kinase 3-induced tumor suppression and chemosensitization. Mol Cell Biol. 2007;27(11):4006-17.

35. Tong J, Wang P, Tan S, Chen D, Nikolovska-Coleska Z, Zou F, et al. Mcl-1 degradation is required for targeted therapeutics to eradicate Colon Cancer cells. Cancer Res. 2017;77(9):2512-21.

36. Arai $\mathrm{S}$, Jonas $\mathrm{O}$, Whitman MA, Corey E, Balk SP, Chen S. Tyrosine kinase inhibitors increase MCL1 degradation and in combination with BCLXL/BCL2 inhibitors drive prostate Cancer apoptosis. Clin Cancer Res. 2018;24(21): 5458-70.

37. Nalluri S, Peirce SK, Tanos R, Abdella HA, Karmali D, Hogarty MD, et al. EGFR signaling defines $\mathrm{Mcl}(-) 1$ survival dependency in neuroblastoma. Cancer Biol Ther. 2015:16(2):276-86.

38. Cao F, Gong YB, Kang XH, Lu ZH, Wang Y, Zhao KL, et al. Degradation of $\mathrm{MCL}-1$ by bufalin reverses acquired resistance to osimertinib in EGFRmutant lung cancer. Toxicol Appl Pharmacol. 2019;379:114662. 
39. Shi P, Oh YT, Deng L, Zhang G, Qian G, Zhang S, et al. Overcoming acquired resistance to AZD9291, a third-generation EGFR inhibitor, through modulation of MEK/ERK-dependent Bim and MCl-1 degradation. Clin Cancer Res. 2017;23(21):6567-79.

40. Fletcher S. MCL-1 inhibitors - where are we now (2019)? Expert Opin Ther Pat. 2019;29(11):909-19.

41. Magiera MM, Mora S, Mojsa B, Robbins I, Lassot I, Desagher S. Trim17mediated ubiquitination and degradation of $\mathrm{Mcl}-1$ initiate apoptosis in neurons. Cell Death Differ. 2013;20(2):281-92.

42. Zhong Q, Gao W, Du F, Wang X. Mule/ARF-BP1, a BH3-only E3 ubiquitin ligase, catalyzes the polyubiquitination of $\mathrm{Mcl}-1$ and regulates apoptosis, Cell. 2005;121 (7):1085-95

43. Tong J, Tan S, Zou F, Yu J, Zhang L. FBW7 mutations mediate resistance of colorectal cancer to targeted therapies by blocking Mcl-1 degradation. Oncogene. 2017;36(6):787-96.

44. Wu X, Luo Q, Zhao P, Chang W, Wang Y, Shu T, et al. MGMT-activated DUB3 stabilizes MCL1 and drives chemoresistance in ovarian cancer. Proc Natl Acad Sci U S A. 2019;116(8):2961-6.

45. Sun H, Kapuria V, Peterson LF, Fang D, Bornmann WG, Bartholomeusz G, et al. Bcr-Abl ubiquitination and Usp9x inhibition block kinase signaling and promote CML cell apoptosis. Blood. 2011;117(11):3151-62.

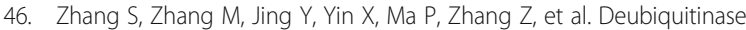
USP13 dictates MCL1 stability and sensitivity to BH3 mimetic inhibitors. Nat Commun. 2018;9(1):215.

47. Ye M, Zhang $Y$, Zhang $X$, Zhang J, Jing $P$, Cao L, et al. Targeting FBW7 as a strategy to overcome resistance to targeted therapy in non-small cell lung Cancer. Cancer Res. 2017;77(13):3527-39.

\section{Publisher's Note}

Springer Nature remains neutral with regard to jurisdictional claims in published maps and institutional affiliations.

Ready to submit your research? Choose BMC and benefit from:

- fast, convenient online submission

- thorough peer review by experienced researchers in your field

- rapid publication on acceptance

- support for research data, including large and complex data types

- gold Open Access which fosters wider collaboration and increased citations

- maximum visibility for your research: over $100 \mathrm{M}$ website views per year

At BMC, research is always in progress.

Learn more biomedcentral.com/submissions 